\title{
Фотолюминесцентные свойства нанородов ZnO, синтезированных различными методами
}

\author{
(C) С.С. Курбанов ${ }^{1}$, Ш.З. Уролов ${ }^{1}$, З.Ш. Шаймарданов ${ }^{1}$, Х.Д. Чо ${ }^{2}$, Т.В. Канг ${ }^{2}$ \\ ${ }^{1}$ Институт ионно-плазменных и лазерных технологий академии наук Республики Узбекистан, \\ 100125 Ташкент, Узбекистан \\ ${ }^{2}$ Исследовательский центр квантово-функциональных полупроводников, Донгукский университет, \\ 100715 Сеул, Республика Корея \\ E-mail: saidislam_kurbanov@yahoo.com
}

(Получена 28 июня 2017 г. Принята к печати 29 ноября 2017 г.)

Исследованы фотолюминесцентные свойства нанородов ZnO, синтезированных низкотемпературным гидротермальным и высокотемпературным парофазным методами. При комнатной температуре спектр люминесценции нанородов $\mathrm{ZnO}$, выращенных высокотемпературным парофазным методом, содержит только один, сильный УФ пик при 382 нм. В то же время спектры люминесценции образцов нанородов $\mathrm{ZnO}$, выращенных низкотемпературным гидротермальным методом, но с использованием различных химических реагентов, наряду с УФ пиком также содержат фиолетовую или желто-оранжевую полосы при $\sim 401$ и $\sim 574$ нм соответственно. Фиолетовая полоса люминесценции приписана дефектам или комплексам вакансии цинка, а желто-оранжевая полоса отнесена к дефектам, связанным с междоузельным кислородом.

DOI: 10.21883/FTP.2018.07.46048.8673

\section{1. Введение}

Наноструктурный полупроводник оксид цинка $(\mathrm{ZnO})$ вызывает повышенный интерес благодаря его большим возможностям в фундаментальных исследованиях и практическом применении. В аспекте фундаментальных исследований наноструктурный $\mathrm{ZnO}$ является удобным объектом для изучения квантово-размерных и поверхностных эффектов из-за его развитой поверхности. Для практического применения оксид цинка является перспективным материалом в создании светоизлучающих приборов УФ диапазона, поскольку при комнатной температуре $\mathrm{ZnO}$ имеет широкую запрещенную зону 3.37 эВ [1]. В этой связи квазиодномерные (1D) $\mathrm{ZnO}$ наноматериалы (особенно пространственно ориентированные нанороды и нанопроволоки), как ожидается, найдут применение в создании УФ лазеров, работающих при комнатной температуре $[2,3]$. Эти ожидания базируются на большой энергии связи (60 мэВ) свободного экситона в оксиде цинка, которая позволяет и при температуpax выше комнатной реализовать лазерную генерацию вследствие экситонной рекомбинации [4,5]. Понимание оптических, электрических и структурных свойств этих материалов является важным этапом в применении их в различных оптических и электронных устройствах.

Нанороды или нанопроволоки $\mathrm{ZnO}$ могут быть выращены как парофазным методом, так и из раствора. Низкотемпературный гидротермальный синтез представляет возможность резко снизить стоимость продукта и выращивать структуры на больших площадях, так как исключает высокие температуры и требования к высокому вакууму. Более того, обычно температура синтеза ниже $100^{\circ} \mathrm{C}$, что позволяет использовать в качестве подложки пластик и другие материалы, непригодные в случае высоких температур. Парофазный метод позволяет синтезировать высококачественные, хорошо ориентированные нанороды $\mathrm{ZnO}$. Более того, нанороды $\mathrm{ZnO}$, выращенные этим методом проявляют высокую излучательную способность в УФ области и интенсивность люминесценции в этих нанородах на несколько порядков больше чем в таковых, синтезированных гидротермальным методом. Одно из преимуществ парофазного метода перед молекулярно-лучевой эпитаксией заключается в том, что в парофазном методе ставятся относительно низкие требования к вакуумной системе, в то время как для молекулярно-лучевой эпитаксии требуется ультравысокий вакуум. Изменяя методы и условия синтеза, можно выращивать нанороды ZnO как с различными диаметром и длиной, так и с варьируемыми излучательными характеристиками.

Обычно спектр люминесценции материалов оксида цинка, как и нанородов и наночастиц, состоит из двух частей: краевой люминесценции в районе 380 нм и широкой полосы в видимой области, обусловленной дефектами в структуре. Последняя полоса люминесценции в зависимости от методов синтеза и способов последующей обработки может содержать фиолетовоголубую (390-460 нм), и(или) зеленую (500-520 нм), и(или) желто-оранжевую (560-600 нм), и(или) красную $(650$ нм $)$ полосы. Желто-оранжевая полоса люминесценции (ПЛ) приписывается межузельному кислороду или комплексам, связанным с кислородом [6-10]. Она часто наблюдается в материалах оксида цинка, выращенных из водных растворов при относительно низких температурах. В противоположность этому зеленая ПЛ наблюдается в материалах $\mathrm{ZnO}$, синтезированных в условиях с дефицитом кислорода или после высокотемпературного отжига. Она приписывается дефектам, связанным с вакансией кислорода $[1,11,12]$. Фиолетовоголубая полоса может быть разделена на фиолетовую 
около 400 нм и голубую в районе $420-460$ нм полосы свечения. Для фиолетовой ПЛ предложено несколько механизмов излучения: вакансия цинка $(\mathrm{VZn})[10,13-15]$, кислородный дефект перестановки (антисайт кислород) $\left(\mathrm{O}_{\mathrm{Zn}}\right)$ [16], и межузельный цинк $\left(\mathrm{Zn}_{i}\right)$ [17]. Полоса свечения, обусловленная дефектами $\mathrm{ZnO}$, является каналом утечки возбуждения. Соотношение интенсивностей краевой люминесценции и дефектной полосы свечения в материалах $\mathrm{ZnO}$ зависит от условий синтеза и может быть использовано как показатель оптического качества структуры.

В настоящей работе обсуждаются люминесцентные свойства нанородов $\mathrm{ZnO}$, выращенных разными методами. Наши исследования показали, что спектры люминесценции нанородов $\mathrm{ZnO}$, синтезированных низкотемпературным гидротермальным методом, но с применением различных химикатов, содержат разные полосы свечения. Эти спектры, наряду с краевой люминесценцией, также содержат фиолетовую или желто-оранжевую полосы. Полученные результаты указывают, что фиолетовая и желто-оранжевая полосы люминесценции могут быть обусловлены дефектами, ассоциированными с вакансией цинка или комплексами вакансии цинка и дефектами, связанными с межузельным кислородом соответственно.

\section{2. Эксперимент}

Нанороды ZnO были выращены с использованием двух модификаций низкотемпературного гидротермального метода и методом высокотемпературного парафазного транспорта. В первом случае (образец 1) процедура синтеза заключалась в следующем: цинк ацетат дигидрат $\mathrm{Zn}\left(\mathrm{CH}_{3} \mathrm{COO}\right)_{2} \cdot 2 \mathrm{H}_{2} \mathrm{O}(0.016 \mathrm{M})$ при комнатной температуре был растворен в деионизированной воде. Затем раствор аммиака $\mathrm{NH}_{4} \mathrm{OH}(0.095 \mathrm{M})$ был добавлен в этот раствор при интенсивном перемешивании до тех пор, пока $\mathrm{pH}$ фактор раствора не стал равным 8. Полученный раствор был перемещен в стальной автоклав с внутренним тефлоновым покрытием. Затем предварительно подготовленные стеклянные пластинки с проводящей оксид индия-олова (ITO) пленкой и зародышами $\mathrm{ZnO}$ активной поверхностью вниз были помещены на дно автоклава. В заключение автоклав плотно закрывался и помещался в термостабилизированную печь. Гидротермальный синтез производился при температуре $85^{\circ} \mathrm{C}$ в течение 5 ч.

Во втором гидротермальном способе (образец 2) водные растворы нитрат цинка гексогидрата $\left(\mathrm{Zn}\left(\mathrm{NO}_{3}\right)_{2} \cdot 6 \mathrm{H}_{2} \mathrm{O}\right)$ и гексаметилтетрамина $\left(\mathrm{C}_{6} \mathrm{H}_{12} \mathrm{~N}_{4}\right)$ приготавливались отдельно и затем смешивались. Концентрация обоих растворов бралась равной $0.1 \mathrm{M}$. Смесь перемешивалась с помощью магнитной мешалки в течение 30 мин, пока не образовывался прозрачный и однородный раствор. Затем раствор был перемещен в стальной автоклав с внутренним тефлоновым покрытием, где предварительно были помещены активной поверхностью вниз подготовленные стеклянные пластинки с проводящей ITO пленкой и зародышами $\mathrm{ZnO}$. Гидротермальная реакция протекала в термостабилизированной печи при температуре $90^{\circ} \mathrm{C}$ в течение 5 ч.

После окончания реакции синтеза автоклав вынимался из печи и остывал до комнатной температуры при естественных условиях. После охлаждения образцы извлекались из автоклава и несколько раз промывались в деионизированной воде и высушивались на воздухе.

Подготовка подложек с зародышами $\mathrm{ZnO}$ происходила следующим образом: стеклянные пластинки с проводящей ITO пленкой очищались в ультразвуковой ванне в течение 15 мин в ацетоне и этиловом спирте. Зародыши $\mathrm{ZnO}$ создавались с использованием раствора ацетата цинка дигидрата $\left(\mathrm{Zn}\left(\mathrm{CH}_{3} \mathrm{COO}\right)_{2} \cdot 2 \mathrm{H}_{2} \mathrm{O}\right)$ в этиловом спирте $(5 \mathrm{MM})$. Этот раствор наносился на подложки методом центрофугирования (spin coating), после чего высушивался на воздухе. Процесс повторялся несколько раз, что позволило увеличить плотность образующихся зародышей $\mathrm{ZnO}$. Полученные подложки отжигались на воздухе при температуре $250^{\circ} \mathrm{C}$ в течение 30 мин. Температура отжига немного выше температуры разложения ацетата цинка дигидрата и формирования нанокристаллов $\mathrm{ZnO}$ на подложке.

Массив нанородов $\mathrm{ZnO}$ (образец 3) выращивался на подложке из $\mathrm{Si}(100)$ с применением метода парофазного транспорта при температуре $\left(800-1000^{\circ} \mathrm{C}\right)$ без катализатора. В качестве реагентов использовались Zn $99.999 \%$ чистоты и $\mathrm{O}_{2} 99.995 \%$ чистоты, а азот служил карьерным газом. Все химикаты были аналитической чистоты и использовались без предварительной очистки [18].

Морфология образцов исследовалась с помощью сканирующего электронного микроскопа (СЭМ) (PHILIPS XL-30). Спектры люминесценции регистрировались спектрометром SPEX, оснащенным решеточным монохроматором с фокусным расстоянием 0.75 м и разрешением 0.1 нм. Люминесценция возбуждалась излучением $\mathrm{He}-\mathrm{Cd}$ лазера с длиной волны излучения 325 нм $(3.812$ эВ) и мощностью 50 мВт.

\section{3. Экспериментальные результаты и их обсуждение}

На рис. 1 показаны СЭМ микрофотографии нанородов $\mathrm{ZnO}$, синтезированные тремя методами. Средние значения длины и диаметра нанородов, выращенных гидротермальным методом с использованием ацетат цинка дигидрата и аммиака (образец 1) составляют $\sim 500$ и $25-70$ нм соответственно (рис. 1,a). Средние значения длины и диаметра нанородов, выращенных с использованием нитрат цинка гексогидрата и гексаметилтетрамина (образец 2) больше чем нанородов образца 1 . Диаметр этих нанородов 70-200 нм, а длина 2-2.5 мкм (рис. 1, $b$ ). Высокотемпературный парафазный метод (образец 3) 
позволяет синтезировать нанороды с регулярной гексагональной формой и плоским концом (рис. $1, c)$. Длина нанородов $\sim 15$ мкм и поперечные размеры от 0.5 до 1.4 мкм. Все образцы нанородов $\mathrm{ZnO}$ показывают линии дифракции рентгеновских лучей, характерные для кристаллической гексагональной вюрцит структуры, нанороды ориентированы преимущественно в направлении (002).

На рис. 2 показаны спектры люминесценции нанородов $\mathrm{ZnO}$, регистрированные при комнатной температуре. Спектры люминесценции всех образцов нанородов содержат УФ пик в районе 380 нм, с незначительными отклонениями. УФ пик в образцах 1,2 и 3 расположен при 377,380 и 382 нм соответственно.

В спектре люминесценции образца 1 на длинноволновой стороне УФ пика наблюдается слабое плечо. В противоположность этому, спектр люминесценции

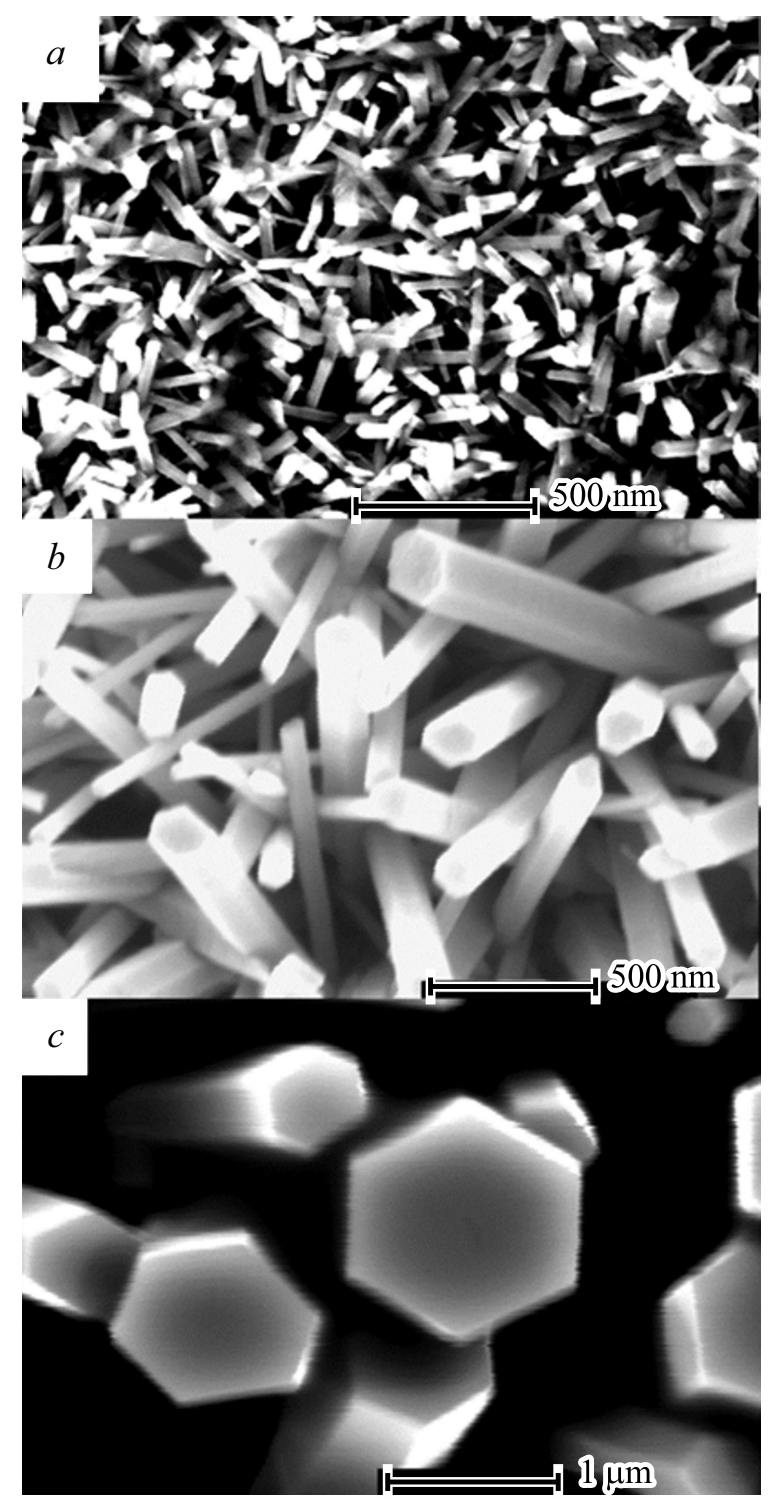

Рис. 1. Микрофотографии нанородов $\mathrm{ZnO}$, полученные сканирующим электронным микроскопом: $a$ - образец 1 , $b$ - образец $2, c-$ образец 3 .

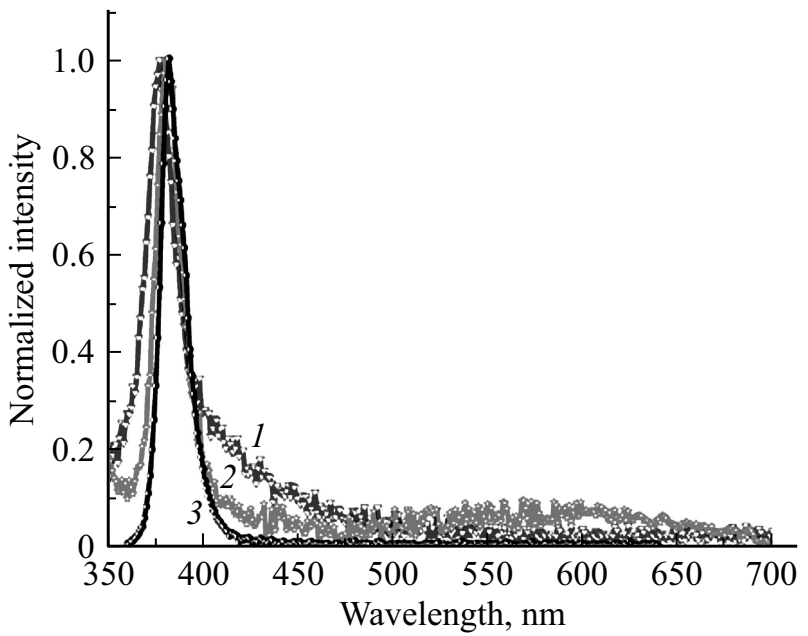

Рис. 2. Спектры люминесценции нанородов $\mathrm{ZnO}: 1$ - образец 1,2 - образец 2 и 3 - образец 3 . Спектры получены при комнатной температуре.

образца 2 в видимой области спектра содержит слабую, широкую полосу в районе 550-600нм. Среди исследованных образцов нанороды $\mathrm{ZnO}$, выращенные высокотемпературным парафазным методом показали очень сильный УФ пик в своих спектрах люминесценции. Кроме УФ пика, другие полосы люминесценции в видимой области спектра не проявляются (рис. 2, 3).

Согласно литературе, УФ пик, наблюдаемый во всех образцах, отнесен к краевой люминесценции оксида цинка, а именно к свечению свободного экситона. Различия в положениях максимума могут быть связаны с различными размерами нанородов. Как видно из рис. 1, нанороды образца 3 имеют наибольший диаметр по сравнению с другими образцами. Нанороды образца 1 имеют самый маленький диаметр и их средний диаметр почти в 3 и в 20 раз меныше таковых для нанородов образцов 2 и 3 соответственно. Таким образом, разные положения максимумов УФ пика можно объяснить некоторым размерным эффектом из-за разницы в диаметрах нанородов.

Как было указано выше, высокая интенсивность краевой и низкая интенсивность дефектной люминесценции являются показателем качества нанородов ZnO. Спектр люминесценции нанородов образца 1 можно разложить на две лоренцовы компоненты с максимумами при 377 и 401 нм (рис. 3, $a$, пунктирная линия). В спектре люминесценции нанородов образца 2 полоса в районе 400 нм не проявляется, но этот спектр содержит широкую желто-оранжевую полосу в районе $\sim 578$ нм (рис. $3, b$, пунктирная линия).

Учитывая, что нанороды были синтезированы без посторонних добавлений, фиолетовая и желто-оранжевая полосы люминесценции можно приписать к собственным дефектам и их комплексам в ZnO. Как было сказано во Введении, желто-оранжевая полоса часто наблюдается в наноматериалах оксида цинка, выращенных из вод- 

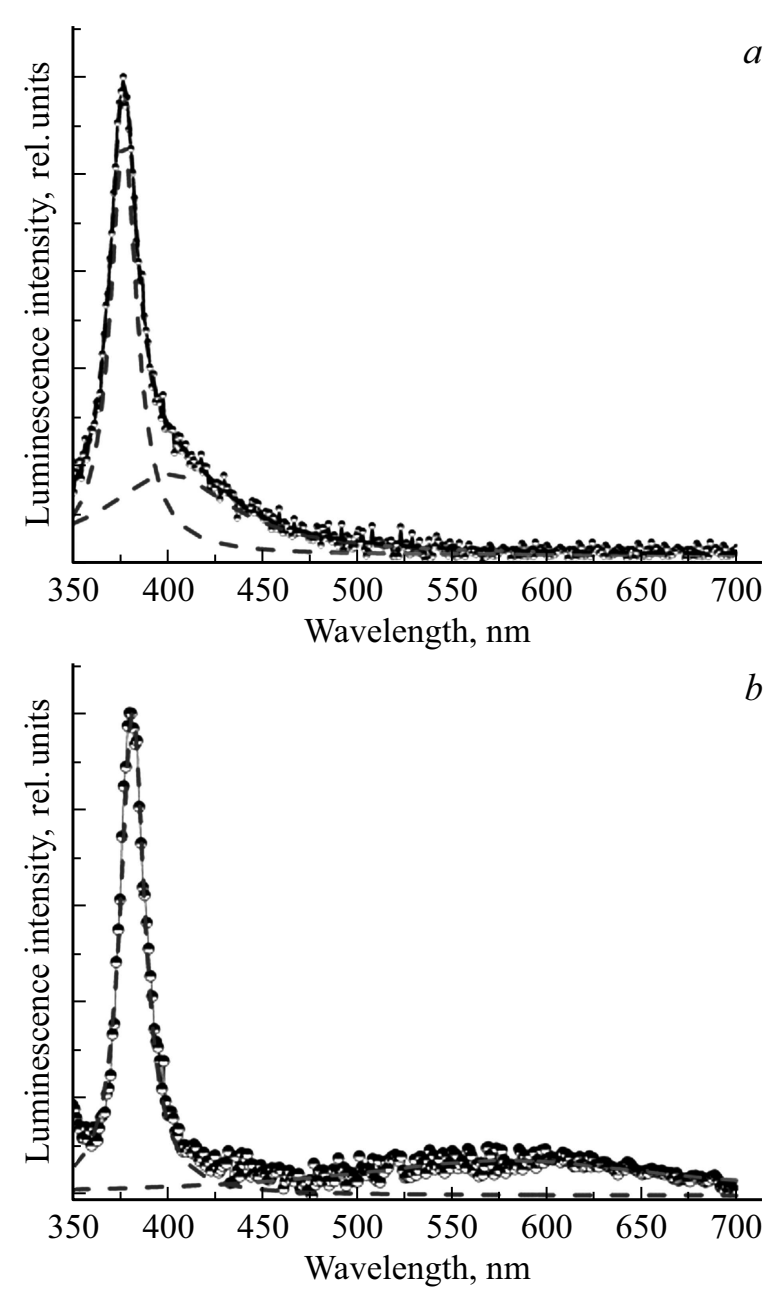

Рис. 3. Разложение спектров люминесценции нанородов $\mathrm{ZnO}$ на лоренцевы компоненты (пунктирные линии): $a$ - образец 1 , $b$ - образец 2 .

ных растворов при относительно низких температурах, и обычно приписывается межузельному кислороду или комплексам, образованным с участием кислорода [6-10]. Учитывая эти обстоятельства, полосу свечения при $\sim 574$ нм, наблюдаемую в образце 2 можно отнести к дефектам, связанным с междоузельным кислородом.

Имеется множество публикаций, где сообщается о наблюдении при комнатной температуре фиолетовой полосы люминесценции, расположенной в области 390-420 нм (2.95-3.18 эВ) [10,13,14,19-21]. Например, в пленках $\mathrm{ZnO}$, полученных импульсным лазерным напылением наблюдались полосы катодолюминесценции при 405 нм [10] и фотолюминесценции при $400 \mathrm{Hм}$ (3.1 эВ) [21]. Фиолетовая полоса свечения, отнесенная к $\mathrm{VZn}$-центрам, появлялась, когда давление кислорода при синтезе было максимальным. Полосы люминесценции при 401 нм (3.09 эВ) и 413-424 нм были обнаружены в пленках $\mathrm{ZnO}$, выращенных радиочастотным магнетронным распылением при избытке кислорода [13] и в пленках $\mathrm{ZnO}$, синтезированных на кварцевых подложках окислением металлического цинка [19]. В последнем случае максимум полосы люминесценции смещается от 424 к 413 нм, а ее интенсивность растет с увеличением давления кислорода. Эти полосы также были приписаны вакансиям цинка.

Анализ литературных данных, посвященных свойствам фиолетовой полосы люминесценции, показывает, что она наблюдается в структурах $\mathrm{ZnO}$, выращенных в условиях с избытком кислорода, независимо от способов синтеза. Таким образом, имеется реальное влияние концентрации кислорода, т.е. избытка кислорода на интенсивность и положение фиолетовой полосы люминесценции. Основываясь на этих данных и наших результатах, мы можем предположить, что фиолетовая полоса люминесценции, зарегистрированная в нанородах $\mathrm{ZnO}$, также обусловлена дефектами, связанными с вакансиями цинка или их комплексами.

Это заключение также поддерживается теоретическими исследованиями [22,23]. Как было показано, при синтезе $\mathrm{ZnO}$ с избытком кислорода межузельный кислород и вакансия цинка являются доминирующими дефектами и их энтальпия образования меньше, чем у других дефектов. Как было предсказано, для вакансии цинка переходный уровень $(0 /-1)$ лежит при $\sim 0.45$ эВ [22] или $\sim 0.3$ эВ [23], а переходный уровень $(-1 /-2)$ расположен при $\sim 0.8$ эВ [22] или 0.7 эВ [23] выше потолка валентной зоны. Исходя из этого переход электрона из зоны проводимости на однозарядный акцепторный уровень вакансии цинка может дать люминесценцию с длиной волны $401 \mathrm{Hм}$ (3.09эВ), что согласуется с предсказанной энергией перехода.

Относительно высокая интенсивность фиолетовой люминесценции нанородов $\mathrm{ZnO}$ в образце 1 по сравнению с образцом 2 объясняется изменением соотношения площади поверхности нанородов и их объема с изменением диаметра нанородов. Как известно, наноразмерные материалы имеют большое отношение поверхности к объему, и такая особенность наноматериалов критично действует на их электронные и оптические свойства. Нанороды $\mathrm{ZnO}$ с маленьким диаметром имеют более высокое значение отношения поверхности к объему, чем нанороды с большим диаметром. Для стержня, имеющего длину $h$ и радиус $r$, отношение поверхности стержня к его объему $R$ может быть определено следующим выражением:

$$
R=\frac{S}{V}=\frac{2 \pi r^{2}+2 \pi r h}{\pi r^{2} h}
$$

Оценка средних значений отношения поверхности к объему показала, что для нанородов $\mathrm{ZnO}$ в образце 1 оно равняется 0.06, а для нанородов в образце 2 оно в три раза меньше и равняется 0.02. Очевидно, что нанороды в образце 1 имеют более развитую поверхность чем нанороды в образце 2, и в них явления, связанные с поверхностью, должны проявляться более выражено. Зубайга (Zubiaga) и соавторы, базируясь на экспериментах 
с применением аннигиляции позитронов, показали, что в пленках $\mathrm{ZnO}$ концентрация вакансий цинка уменьшается с увеличением толщины пленки [24]. Этот результат является доказательством того, что центры вакансии цинка преимущественно расположены на поверхности оксида цинка и больше подвержены эффектам, связанным с поверхностью. С другой стороны, как было сообщено в работе [25], желто-оранжевая полоса люминесценции не чувствительна к модификациям поверхности наноструктур и может быть обусловлена дефектами, расположенными не на поверхности, а в объеме наноструктуры. Эти результаты также подтверждают наши наблюдения (в образце 1 наблюдается более интенсивная фиолетовая полоса и слабая желто-оранжевая полоса, а в образце 2 наоборот) и выводы относительно природы и влияния изменения соотношения поверхности нанородов и их объема на интенсивность фиолетовой полосы люминесценции.

Отсутствие фиолетовой полосы люминесценции в нанородах $\mathrm{ZnO}$, выращенных высокотемпературным парафазным методом (образец 3), можно объяснить сбалансированной концентрацией кислорода в ходе роста этих нанородов. Этот вывод также находится в согласии с высокой интенсивностью УФ полосы и отсутствием каких-либо полос, обусловленных дефектами.

Хотя некоторые аспекты приведенных наблюдений остаются не до конца раскрытыми, изложенные результаты дают несомненно полезную информацию и могут прояснить природу различных полос свечения, приписываемых дефектам в нанородах $\mathrm{ZnO}$, синтезированных различными методами, а также пролить свет на происхождение фиолетовой полосы люминесценции. Исследования структурных и электрических свойств нанородов $\mathrm{ZnO}$ продолжаются и будут представлены в ближайшем будущем.

\section{4. Заключение}

Нанороды $\mathrm{ZnO}$ были синтезированы двумя низкотемпературными гидротермальными методами и высокотемпературным парафазным методом. При комнатной температуре нанороды ZnO, выращенные высокотемпературным парафазным методом проявляют только одну, очень сильную УФ полосу люминесценции при 382 нм. Хотя два образца нанородов $\mathrm{ZnO}$ были синтезированы низкотемпературным гидротермальным методом, но с использованием разных химикатов их спектры люминесценции наряду с УФ полосой содержат фиолетовую или желто-оранжевую полосы при $\sim 401$ и $\sim 574$ нм соответственно. Наблюдаемая УФ полоса отнесена к краевой люминесценции $\mathrm{ZnO}$. Учитывая то, что полосы люминесценции, связанные с дефектами структуры, регистрировались в нанородах $\mathrm{ZnO}$, синтезированных в условиях с избытком кислорода, фиолетовая полоса люминесценции отнесена к дефектам вакансии цинка или ее комплексам, а желто-оранжевая полоса идентифи- цирована с дефектами межузельного кислорода. Проявление только одной из полос в спектре люминесценции (фиолетовой или желто-оранжевой) возможно обусловлено вариациями соотношения площади поверхности нанородов и их объема с изменением их диаметра.

Настоящая работа выполнена при поддержке гранта ОТ-Ф2-52 Программы фундаментальных исследований Республики Узбекистан и гранта № 2014R1A2A1A12066298 Национального фонда исследований Кореи (NRF), финансируемого Министерством образования, науки и технологии Республики Корея.

\section{Список литературы}

[1] Ü. Özgür, Ya.I. Alivov, C. Liu, A. Teke, M.A. Reshchikov, S. Doğan, V. Avrutin, S.-J. Cho, H. Morkoç. J. Appl. Phys., 98, 041301 (2005).

[2] Z.K. Tang, G.K.L. Wang, P. Yu. Appl. Phys. Lett., 72, 3270 (1998).

[3] Q.X. Zhao, M. Willander, R.E. Morjan. Appl. Phys. Lett., 83, 165 (2003).

[4] Ü. Özgür, Ya.I. Alivov, C. Liu. J. Appl. Phys., 98, 04130 (2005).

[5] M.H. Huang, S. Mao, H.N. Feick. Science, 292, 1897 (2001).

[6] L. Wu, L. Wu, X. Pan, F. Kong. Opt. Mater., 28, 418 (2006).

[7] J.W.P. Hsu, D.R. Tallant, R.L. Simpson, N.A. Missert, R.G. Copeland. Appl. Phys. Lett., 88, 252103 (2006).

[8] A.B. Djuriši'c, Y.H. Leung, K.H. Tam, L. Ding, W.K. Ge, H.Y. Chen, S. Gwo. Appl. Phys. Lett., 88, 103107 (2006).

[9] X. Liu, X. Wu, H. Cao, R.P.H. Chang. J. Appl. Phys., 95, 3141 (2004).

[10] X.L. Wu, G.G. Siu, C.L. Fu, H.C. Ong. Appl. Phys. Lett., 78, 2285 (2001).

[11] K. Vanheusden, W.L. Warren, C.H. Seager, D.R. Tallant, J.A. Voigt. J. Appl. Phys., 79, 7983 (1996).

[12] F.H. Leiter, H.R. Alves, A. Hofstaetter, D.M. Hofmann, B.K. Meyer. Phys. Status Solidi B, 226, R4 (2001).

[13] S.H. Jeong, B.S. Kim, B.S. Lee. Appl. Phys. Lett., 82, 2625 (2003).

[14] G. Hua, Y. Zhang, Ch. Ye, M. Wang, L. Zhang. Nanotechnology, 18, 145605 (2007).

[15] S.S. Kurbanov, G.N. Panin, T.W. Kim, T.W. Kang. J. Luminesc., 129, 1099 (2009).

[16] Q.X. Zhao, P. Klason, M. Willander, H.M. Zhong, W. Lu, J.H. Yang. Appl. Phys. Lett., 87, 211912 (2005).

[17] B. Kumar, B. Gonga, S. Vicknesh, S.J. Chua, S. Tripathy. Appl. Phys. Lett., 89, 141901 (2006).

[18] S.S. Kurbanov, H.D. Cho, T.W. Kang. Optics Commun., 284, 240 (2011).

[19] X.M. Fan, J.S. Lian, L. Zhao, Y.H. Li. Appl. Surf. Sci., 252, 420 (2005).

[20] R.B. Kale, Y.J. Hsu, Y.F. Lin, S.Y. Lu. Sol. St. Commun., 142, 302 (2007).

[21] A.A. Chaaya, R. Viter, M. Bechelany, Z. Alute, D. Erts, A. Zalesskaya, K. Kovalevskis, V. Rouessac, V. Smyntyna, P. Miele, J. Beilstein. Nanotechnol., 4, 690 (2013).

[22] A.F. Kohan, G. Ceder, D. Morgan, C.G. Van de Walle. Phys. Rev. B, 61, 15019 (2000).

[23] P. Erhart, K. Albe, A. Klein. Phys. Rev. B, 73, 205203 (2006). 
[24] A. Zubiaga, F. Tuomisto, F. Plazaola, K. Saarinen, J.A. Garcia, J.F. Rommeluere, J. Zuñiga-Pérez, V. Muñoz-Sanjos'e. Appl. Phys. Lett., 86, 042103 (2005).

[25] D. Li, Y.H. Leung, A.B. Djurišì'c, Z.T. Liu, M.H. Xie, S.L. Shi, S.J. Xu, W.K. Chan. Appl. Phys. Lett., 85, 1601 (2004).

Редактор Г.А. Оганесян

\section{Photoluminescence properties of $\mathrm{ZnO}$ nanorods prepared by different methods}

S.S. Kurbanov ${ }^{1}$, Sh.Z. Urolov ${ }^{1}$, Z.Sh. Shaymardanov ${ }^{1}$, H.D. Cho ${ }^{2}$, T.W. Kang ${ }^{2}$

${ }^{1}$ Institute of Ion-Plasma and Laser Technologies,

Uzbekistan Academy of Sciences,

100125 Tashkent, Uzbekistan

${ }^{2}$ Quantum-Functional Semiconductor Research Center, Dongguk University, Seoul,

100715 Seoul, Republic of Korea

Abstract Photoluminescence properties of $\mathrm{ZnO}$ nanorods synthesized using low temperature hydrothermal routes and a high temperature vapor-phase transport method are studied. At room temperature, $\mathrm{ZnO}$ nanorods grown by the high temperature vaporphase transport method exhibited only one, very strong UV emission peak at $382 \mathrm{~nm}$. PL spectra from the $\mathrm{ZnO}$ nanorod samples grown by the low temperature hydrothermal routes but using different chemicals, along with the UV band, contain violet or yellow-orange emission bands located at $\sim 401$ and $\sim 574 \mathrm{~nm}$, respectively. The violet band is attributed to $\mathrm{Zn}$ vacancy related defects or their complexes, and the yellow-orange broad emission band is ascribed to oxygen interstitial related defects. 